\title{
The Effect of Progressive Relaxation Training versus Aromatherapy on Primary Dysmenorrhea, Egypt
}

\author{
HALA M. HANFY, Ph.D.*; HOSSAM ELDIN H. KAMEL, M.D.**; WAFA M. KAMAL, Ph.D.* and \\ SALWA M. MAHMOUD, M.Sc.*** \\ The Department of Physical Therapy for Women's Health, Faculty of Physical Therapy, Cairo University*, \\ The Department of Obstetrics and Gynecology, Faculty of Medicine, El-Azhar University** and \\ Physiotherapy Specialist of Women's Health, Suez General Hospital, Suez***, Egypt
}

\begin{abstract}
Background: Dysmenorrhea is a common gynecologicalcomplaint among young females with a major effect on work efficiencyand quality of life. The most common symptoms are pain in the lowerabdomen and back may reach to inner thighs, and other symptoms mayoccur such as breast tenderness, nausea, vomiting, diarrhea, fatigue, andheadache. This study was conducted to evaluate the effect of progressiverelaxation training versus aromatherapy on primary dysmenorrhea.

Aim of Study: To study the effect of progressive relaxation training versus aromatherapy on primary dysmenorrhea.

Subjects and Methods: Forty virgin girls were included in the study. Their age ranged from 16-25 years. They were randomly divided intotwo equal groups: Group (A): Received progressive relaxation training. Group (B): Received aromatherapy.

VAS scale and serum cortisol level blood test were used for assessment before and after successive eight weeks of treatment for both groups.

Results: Post-treatment results revealed that there was a significant improvement in (VAS) scores and serumcortisol level in both groups however the difference between groups wasnon-significant there was a significant decrease in VAS score and serumcortisol level in each group.
\end{abstract}

Conclusion: Aromatherapy has the same beneficial effect of progressive relaxations training on improvement of pain in primary dysmenorrhea.

Key Words: Aromatherapy - Progressive relaxation training - Primary dysmenorrhea.

\section{Introduction}

DYSMENORRHEA is a common gynecological complaint among young females with a major effect on work efficiency and quality of life [1].

Correspondence to: Dr. Hala M. Hanfy, The Department of Physical Therapy for Women's Health, Faculty of Physical Therapy, Cairo University
It is defined as pain during menstruation in females, always starting during adolescence; there are two types: Primary and secondary dysmenorrhea [2].

Primary dysmenorrhea occurs without pelvic pathology [3]; the most common symptoms are pain in the lower abdomen and back may reach to inner thighs, and other symptoms may occur such as breast tenderness, nausea, vomiting, diarrhea, fatigue, and headache [4].

Primary dysmenorrhea causes are not accurately identified, but most complaints may be because of prostaglandins (PG) secretion, particularly (PGF2(x). Prostaglandins are important stimulators of uterine contractility. Excessive production of endometrial Prostaglandins may be one of the main causes of strong uterine contractions and temporarily ischemia occurs in the uterus; this ischemia decreases uterine oxygen and results in severe abdominal pain [5]

Medicinal and non-medicinal treatment methods such as anti-inflammatory pain relievers, Cyclooxygenase controller drugs, contraceptives, psychotherapy, physical therapy such as use of heat and sports such as jogging and Yuga are applied for menstrual pains treatment [6].

Exercise today is an integral part of normal life for many women. It is clear that there are many health benefits for women who exercise regularly and in moderation. Exercise improves cardiovascular status, increased bone mineral content; improve dysmenorrhea and premenstrual syndrome symptoms [7]. 
Study found that progressive relaxationtechnique is easy to adopt, self-administered with no side effects which has beneficial effect in pain reduction. Reducing absenteeism thus improving quality of life, self-esteem of the subjects can also be improved by using those simple relaxation exercises [8].

One of the most popular is aromatherapy massage. It involves gentle massage of areas of the body, using aromatic essential oils extracted from plants and flowers. Its aim is to promote relaxation and release of tension. It is suggested that the aroma of the oils helps to achieve this by stimulating the limbic area of the brain associated with emotions and level of arousal [9]. From a physiological view that was explained by Re et al., [10] has an element of Linalool in lavender could inhibit the release of acetylcholine, which changes the functions related to the channels of ions on the neuromuscular synapses. Moreover, Linalyl acetate component has a narcotic effect and linalool works as a sedative agent. Accordingly, these functions rationalize the pain-reducingeffect of lavender. The current study was conducted to investigate the effect of progressive relaxation training versus aromatherapy on improving primary dysmenorrhea.

\section{Subjects and Methods}

\section{Subjects:}

This study was carried upon forty virgin girls diagnosed with primary dysmenorrhea. They were selected from the outpatient clinic of Obstetrics \& Gynecology and the school of nursing in Suez general Hospital in Suez, in the period from October 2017 to December 2018. On the following criteria.

\section{Inclusion criteria:}

Forty virgin girls were diagnosed with primary dysmenorrhea, their age was ranged from 16-25 years, and their body mass index was ranged from $20-27 \mathrm{~kg} / \mathrm{m}^{2}$.

\section{Exclusive criteria:}

Girls were excluded from the study if they had irregular or infrequent menstrual cycles, hyperthyroidism, pelvic pathology, endometriosis and mental health problem such as depression and anxiety with BMI $<25 \mathrm{~kg} / \mathrm{m}^{2}$.

\section{Methods:}

1- Informed consent form: (Appendix I).

2- Recording data sheet: All data and information of each patient who participated in this studyincluding name, age, address, weight and height were recorded in recording data sheet (Appendix II).

3- Standard weight and height scale: Was used to measure weight $\&$ height to calculate Body Mass Index (BMI) for each patient in both groups (A \& B) before beginning of the study.

4- Visual analogue scale: Was used to measure the level of pain for both groups A \& B before and after treatment.

5- Plant materials and aromatic plant oils: Including $2 \%$ (lavender \& rose mary oil).

6- Serum cortisol level: A sample of blood was taken and used to assessthe level of cortisolin the blood which refer to level of pain for both groups A \& B before and after treatment.

7- Progressive relaxation training: Was applied for each participant in group A and they were positioned in comfortable half lying position to apply teaching muscle sense (tense-relax) training for 30 reps once daily 3 times/week for 8 weeks for all patients in group (A).

\section{Procedure:}

All patients were given a full explanation of the protocol of the study and consent form was signed for each patient before participating in the study. Girls demographic data were recorded from the patient file including name, age, weight and height. The clinical details of girls with primary dysmenorrhea such as pain level were determined by VAS and serum cortisol level.

\section{Results}

This study was conducted on 40 women suffered from primary dysmenorrhea admitted to the outpatient clinics of Obstetrics and Gynecology in Suez general Hospital in Suez, Egypt from the period October to December 2018. They were divided into two groups. Group A, consisted of 20 patients, group B consisted of 20 patients.

\section{1- General characteristics of the girls in both groups:}

The mean values $( \pm \mathrm{SD})$ of age, weight, height and BMI in group A were $18.75 \pm 2.67$ yrs., $61.60 \pm$ $6.98 \mathrm{~kg} ., 164.05 \pm 6.65 \mathrm{~cm}$ and $22.82 \pm 1.26 \mathrm{~kg} / \mathrm{m}^{2}$, respectively. While in group they were $18.80 \pm$ $2.44 \mathrm{yrs} ., 62.80 \pm 6.30 \mathrm{~kg}$., $163.80 \pm 6.65 \mathrm{~cm}$ and 23.36 $\pm 1.29 \mathrm{~kg} / \mathrm{m}^{2}$, respectively. There was no statistical significant difference between the two groups as regards age ( $t=-0.062, p=0.951)$, weight $(t=-0.570$, $p=0.572)$, height $(t=t 0.119, p=0.906)$ and BMI $(t=$ $-1.354, p=0.184$ ) (Table 1). 
Table (1): Physical characteristics in the two studied groups.

\begin{tabular}{lllll}
\hline & $\begin{array}{c}\text { Group (A) } \\
(\mathrm{N}=20)\end{array}$ & \multicolumn{1}{c}{$\begin{array}{c}\text { Group (B) } \\
(\mathrm{N}=20)\end{array}$} & $t$-value & $p$-value \\
\hline Age (yrs.) & $18.75 \pm 2.67$ & $18.80 \pm 2.44$ & -0.062 & $0.951(\mathrm{NS})$ \\
Weight (kg.) & $61.60 \pm 6.98$ & $62.80 \pm 6.30$ & -0.570 & $0.572(\mathrm{NS})$ \\
Height $(\mathrm{cm}) 2$ & $164.05 \pm 6.65$ & $163.80 \pm 6.65$ & 0.119 & $0.906(\mathrm{NS})$ \\
BMI $(\mathrm{kg} / \mathrm{m})$ & $22.82 \pm 1.26$ & $23.36 \pm 1.29$ & -1.354 & $0.184(\mathrm{NS})$ \\
\hline
\end{tabular}

Data are expressed as mean $\pm \mathrm{SD}$

NS: $p>0.05=$ Not Significant

\section{2- Visual Analogue Scale (VAS):}

Within group comparison (intragroup comparison): In group $\mathrm{A}$, there was a statistical significant decrease in the mean value of VAS measured at post-treatment $(4.35 \pm 1.84)$ whencompared with its corresponding value measured at pre-treatment (7.40 \pm 1.67$)$ with $p$-value $=0.001$ (Table 2). Also in group $\mathrm{B}$, there was a statistical significant decrease in the mean value of VAS measured at posttreatment $(4.45 \pm 1.96)$ when compared with its corresponding value measured at pre-treatment (7.55 \pm 1.79$)$ with $p$-value $=0.001$ (Table 2$)$. The percent decrease in VAS in both groups A and B were $41.22 \%$ and $41.06 \%$, respectively.

Table (2): Comparison between mean values of VAS measured pre-and post-treatment in the two studied groups.

\begin{tabular}{lcc}
\hline & Group $(\mathrm{A})(\mathrm{N}=20)$ & Group $(\mathrm{B})(\mathrm{N}=20)$ \\
\hline Pre-treatment & $7.40 \pm 1.67$ & $7.55 \pm 1.79$ \\
Post-treatment & $4.35 \pm 1.84$ & $4.45 \pm 1.96$ \\
Mean difference & 3.05 & 3.10 \\
\% change & $41.22 \downarrow \downarrow$ & $41.06 \downarrow \downarrow$ \\
$p$-value & $0.001(\mathrm{~S})$ & $0.001(\mathrm{~S})$ \\
\hline
\end{tabular}

Data are expressed as mean $\pm \mathrm{SD}$.

S: $p<0.05=$ Significant.

Between groups comparison (inter group comparison): At pre-treatment, there was no statistical significant difference between the mean value of VAS in group A (7.40 \pm 1.67$)$ and its corresponding value in group $B(7.55 \pm 1.79)$ with $\mathrm{F}$-value $=0.075$ and $p$-value $=0.785$ (Table 3 ). ANCOVA test was used to compare the post-treatment values of the two groups on controlling the effect of pretreatment value. The results of VAS revealed that there was no statistical significant difference between its mean value in the two groups $\mathrm{A}(4.35 \pm$ $1.84)$ and $\mathrm{B}(4.45 \pm 1.96)(\mathrm{F}=0.003 \& p=0.958)$.

Table (3): Comparison between mean values of VAS in the two studied groups measured pre-and posttreatment.

\begin{tabular}{lcccc}
\hline & $\begin{array}{c}\text { Group (A) } \\
(\mathrm{N}=20)\end{array}$ & $\begin{array}{c}\text { Group (B) } \\
(\mathrm{N}=20)\end{array}$ & $\begin{array}{c}\text { F- } \\
\text { value }\end{array}$ & $p$-value \\
\hline Pre-treatment & $7.40 \pm 1.67$ & $7.55 \pm 1.79$ & 0.075 & $0.785(\mathrm{NS})$ \\
Post-treatment & $4.35 \pm 1.84$ & $4.45 \pm 1.96$ & 0.003 & $0.958(\mathrm{NS})$ \\
\hline $\begin{array}{l}\text { Data are expressed as mean } \pm \text { SD. } \\
\text { F-value: ANCOVA test. }\end{array}$ & $\quad \mathrm{NS}: p>0.05=$ Not Significant.
\end{tabular}

\section{3- Serum cortisol level:}

Within group comparison (intra group comparison): In group A, there was a statistical significant decrease in the mean value of serum cortisol level measured at post-treatment $(13.75 \pm 5.49)$ when compared with its corresponding value measured at pre-treatment $(20.01 \pm 6.64)$ with $p$-value $=0.001$ (Table 4). Also in group B, there was a statistical significant increase in the meanvalue of serum cortisol level measured at post-treatment (15.24 \pm 5.77) when compared with its corresponding value measured at pre-treatment $(20.45 \pm 6.26)$ with $p$ value $=0.001$ (Table 4$)$. The percent decrease in serum cortisol level in both groups A and B were $31.28 \%$ and $25.48 \%$, respectively (Table 4 ).

Table (4): Comparison between mean values of serum cortisol level measured at pre-and post-treatment in the two studied groups.

\begin{tabular}{lcc}
\hline & Group $(\mathrm{A})(\mathrm{N}=20)$ & Group $(\mathrm{B})(\mathrm{N}=20)$ \\
\hline Pre-treatment & $20.01 \pm 6.64$ & $20.45 \pm 6.26$ \\
Post-treatment & $13.75 \pm 5.49$ & $15.24 \pm 5.77$ \\
Mean difference & 6.26 & 5.21 \\
$\%$ change & $31.28 \downarrow \downarrow$ & $25.48 \downarrow \downarrow$ \\
$p$-value & $0.001(\mathrm{~S})$ & $0.001(\mathrm{~S})$ \\
\hline
\end{tabular}

Data are expressed as mean $\pm \mathrm{SD}$.

S: $p<0.05=$ Significant.

Between groups comparison: At pre-treatment, in groups $\mathrm{A}$ and $\mathrm{B}$, the mean values $( \pm \mathrm{SD})$ of serum cortisol level were $20.01 \pm 6.64$ and $20.45 \pm 6.26$, respectively. There was no statistical significant difference between the two groups $(\mathrm{F}=0.048 \& p=$ 0.829) (Table 5). ANCOVA test was used to compare the post-treatment values of the two groups on controlling the effect of pre-treatment value. The results of serum cortisol level revealed that there was no statistical significant difference between the two groups A $(13.75 \pm 5.49)$ and $\mathrm{B}$ $(15.24 \pm 5.77)(\mathrm{F}=2.177 \& p=0.149)$ (Table 5).

Table (5): Comparison between mean values of serum cortisol level in the two studied groups measured at preand post-treatment.

\begin{tabular}{lcccc}
\hline & $\begin{array}{c}\text { Group (A) } \\
(\mathrm{N}=20)\end{array}$ & $\begin{array}{c}\text { Group (B) } \\
(\mathrm{N}=20)\end{array}$ & $\begin{array}{c}\text { F- } \\
\text { value }\end{array}$ & $p$-value \\
\hline Pre-treatment & $20.01 \pm 6.64$ & $20.45 \pm 6.26$ & 0.048 & $0.829(\mathrm{NS})$ \\
Post-treatment & $13.75 \pm 5.49$ & $15.24 \pm 5.77$ & 2.177 & $0.149(\mathrm{NS})$ \\
\hline
\end{tabular}

Data are expressed as mean $\pm \mathrm{SD}$.

F-value: ANCOVA test.

NS $: p>0.05=$ Not Significant.

\section{Discussion}

Dysmenorrhea is cramping pain that accompanies menstruation. According to the American College of Obstetricians and Gynecologists [4] 
dysmenorrhea affects more than half of all women of reproductive age. The current study was conducted to investigate the effect of progressive relaxation training versus aromatherapy on improving primary dysmenorrhea. Forty virgin girls with primary dysmenorrhea they were divided randomly into two equal groups: Group (A) received progressive relaxations training while Group (B): Received aromatherapy. Both groups received the treatment three times aweek for eight successive weeks. All patients were assessed pre and post-treatment using VAS scale and serum cortisol level. Post-treatment results of this study showed that there was asignificant improvement in total (VAS) scores and serum cortisol level in both groups and there was a significant decrease in VAS scores and serum cortisol level in each group.

The result of this study also revealed that the difference between two groups in (VAS) scores and serum cortisol level post-treatment was nonsignificant. This study suggested that topically applied diluted essential oils of lavender and rose mary are effective in alleviating the pain of menstrual cramps.

Nikkhah et al., [11] suggested that Lavender decreases significantly the pain during the early times of deliveries in women. As well, the current finding is supported by another study done by who mentioned that administration of inhaled Lavender through an oxygen face mask can be utilized to decrease the need for analgesics and opioids in immediate post-operative period ofbreast biopsy and in patients undergoing laparoscopic surgeries.

From a physiological view that was explained by Re et al. [10]. Has an element of Linalool in lavender could inhibit the release of acetylcholine, which changes the functions related to the channels of ions on the neuromuscular synapses. Moreover, Linalyl acetate component has a narcotic effect and linalool works as a sedative agent. Accordingly, these functions rationalize the pain-reducing effect of lavender.

In the study of Buckle [12] showed that lavender has been used as an analgesic, sedative and anticonvulsant; clary sage as ananticonvulsant, regulator of menstruation, and to support the actions of estrogen and rose to alleviate uterine problems.

Saekiand Mayumi, [13] showed that lavender is inhaled for 10 minutes, there is an increase in blood flow and a decrease in galvanicskin conduction and systolic blood pressure (indicating a reduction in sympathetic nerve activity.
With respect of the result of the study group (A) findingof this study agreed withrespect of the result of the study group (A) finding of this study agreed with Kiecolt-Glaser et al., [14] study that compared progressive muscle relaxation with social support or no-contact, with the intervention groups of the elderly, seen three times aweek for a month. Only the relaxationgroupwas found to show improvement in mood-a reduction in self-reports of distress-and this wasaccompanied by an upregulation of immune function indexed by an increase in Natural Killer (NK) cell activity and a decrease inantibody levels to the Herpes Simplex Virus (HSV).

With respect of the result of the study group (B) finding of this study agreed with Shaheen et al. [15]. Study that found a significant positive effects of aromatherapy in reducing pain. These results indicate that aromatherapy should be considered a safe addition to current pain management procedures as no adverseeffects were reported in any of the included studies. Additionally, the cost associated with aromatherapy is far less than the cost associated with standard pain management treatment. Although the present meta-analysis indicates a large positive effect for the use of aromatherapy for pain management.

With respect of the result of the study group (B) finding of this study agreed Maasumeh et al. [16], also studied the effect of lavender aromatherapy on pain perception and intrapartum outcome in primiparous women the study was concluded that that aroma therapy decreased the labor pain. In conclusion, this research suggests that aromatherapy has a significant effect on dysmenorrhea. Because there were no side effects, aromatherapy can be regarded as a safe, simple, cost-effective, and viable method of nursing care suitable for all patients and has the same beneficial effect of progressive relaxation training.

With respect of the result of the study group (B) finding of this study agreed Han et al. [17], study that also showed that Aroma therapy is generally performed combining with massage, and it is thought to be safe and effective in treating menstrual pain or dysmenorrhea. Our previous study also showed that aromatherapy is effective in reducing the menstrual pain in college women.

\section{Conclusion:}

This research suggests that aromatherapy has a significant effect on dysmenorrhea. Because there were no side effects, aromatherapy can be regarded as a safe, simple, cost-effective, and viable method 
of nursing care suitable for all patients and has the same beneficial effect of progressive relaxation training.

\section{Acknowledgements:}

The authors would like to express their appreciation for patients who participated in this study and also all the staff and managers of the Suez General Hospital their collaboration.

\section{Funding:}

This research received no specific grant from any funding agency in the public, commercial, or not for-profit sectors.

\section{Declaration of interest:}

The authors declare that there is no conflict of interest in this study. The manuscript has been read and approved by authors.

\section{References}

1- HAREL Z.: Dysmenorrhea in adolescents and young adults: From pathophysiology to pharmacological treatments and management strategies. Expert Opin. Pharmacother., 15: 2661-72, 2008.

2- SHARMA A., TANEJA D., SHARMA P. and SAHA R. Socioeconomic correlates of reproductive morbidity among adolescent girls in Sikkim, India. Asia Pac. J. Public Health, 24: 136-15, 2012.

3- HARADA T.: Dysmenorrhea and endometriosis in young women. Yonago Acta Med., 56: 81-4, 2013.

4- International Journal of Gynecology \& Obstetrics: Apr. 1; 117 (1): 45-7, 2012.

5- MUELLER A., MALTARIS T., SIEMER J., BINDER H., HOFFMANN I., BECKMANN M. and DITTRICH R.: Uterine contractility in response to different prostaglandins: Reslts from extracorporeally perfused non-pregnant swine uteri. Hum. Reprod, 21: 2000-5, 2006.

6- YEKKE FALLAH L., AZIMI H. and SADEGHI T.: The Effect of Aerobic and Walking Exercise on Physical and Psychological Symptoms and Pain of Premenstrual Syn- drome. Iran Journal of Nursing (2008-5923); 25 (80), 2013.

7- ONUR O., GUMUS I., DERBENT A., KAYGUSUZ I., SIMAVLI S., URUN E. and CAKIRBAY H.: Impact of home-based exercise on quality of life of women with primary dysmenorrhoea. South African Journal of Obstetrics and Gynaecology, 18 (1), 2012.

8- LEHRER P.M.: How to relax and how not to relax: A reevaluation of the work of Edmund Jacobson-I. Behaviour Research and Therapy. Jan. 1; 20 (5): 417-28, 1982.

9- GREER S. and MOOREY S.: Adjuvant psychological therapy for patients with cancer: A prospective randomised trial. BMJ, 304: 675/79, 1992.

10- RE L., BAROCCI S., SONNINO, et al.: Linalool modifies the nicotinic receptor-ion channel kinetics at the mouse neuromuscular junction. Pharmacol. Res., 42: 177-82, 2000 .

11-NIKKHAH F., et al.: The effects of lavender aromatherapy on pain following needle insertion into fistula in the hemodialysis patient. Ther. Clin. Pract., 20: 1-4, 2014.

12- BUCKLE J.: Clinical Aromatherapy in Nursing. London: Arnold, 1997.

13- SAEKI Y. and MAYUMI S.: Physiological effects of inhaling fragrances. Int. J. Aromatherapy, 11: 118-25, 2001.

14- KIECOLT-GLASER J.K., GARNER W., SPEICHER C., PENN G.M., HOLLIDAY J.E. and GLASER R.: "Psychosocial enhancement of immunocom-petence in a geriatric population", Hlth. Psychol., 4: 25-41, 1985.

15- SHAHEEN E., LAKHAN, HEATHER SHEAFER, and DEBORAH TEPPER: "The effectiveness of aromatherapy in reducing pain: A systematic review and meta-analysis." Pain research and treatment, 2016.

16- KAVIANI M., AZIMA S., ALAVI N. and TOBEI M.H.: The effect of lavender aromatherapy on pain perception and intrapartum outcome in primiparous women. British Journal of Midwifery, 22 (2): 125-8. doi: 10.12968/ bjom.2014.22.2.125, 2014.

17- S.H. HAN, M.H. HUR, J. BUCKLE, J. CHOI, and M.S LEE: "Effect of aromatherapy on symptoms of dysmenorrhea incollege students: A randomized placebo-controlled clinicaltrial,"Journal of Alternative and Complementary Medicine, Vol. 12, No. 6, pp. 535-41, 2006. 


\section{تآثير العلاج بتمارين الإسترخاء مقابل العلاج العطرى العاب فى حالات عسر الطمث الآولى الآى}

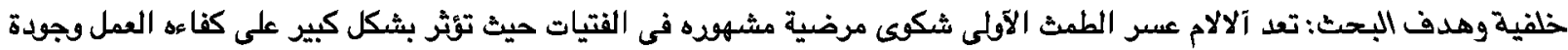

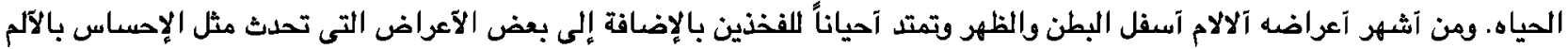

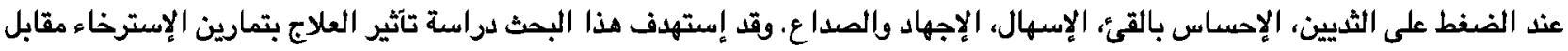

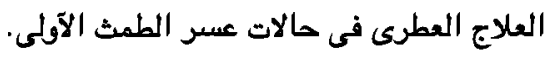

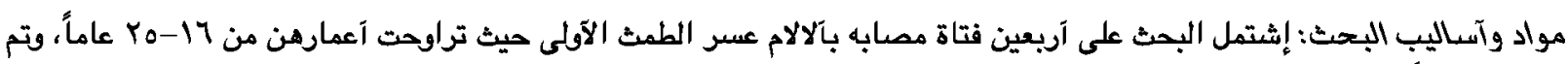

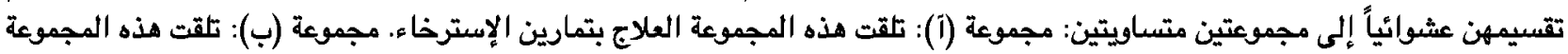

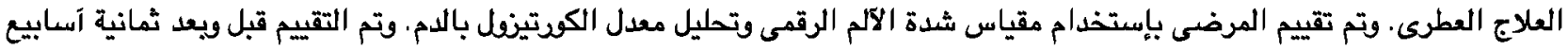
متتالية من التدخل العلاجي.

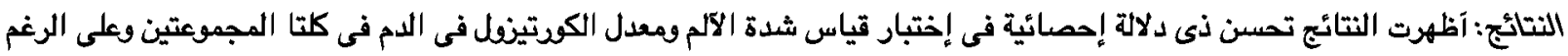

أنه لا يوجد فارق واضح بين المجموعتين إلا آنه وجد آن هناك نقص واضح فى درجة شدة الآلم ومعدل الكوتيزنل في الدم فى كل مجموعة. الخلاصة: إن العلاج العطرى له نفس تآثير العلاج بتمارين الإسترخاء فى حالات آلالام عسر الطمث الآولى. 